\title{
Validation of a UV Spectrometric Method for the Assay of Tolfenamic Acid in Organic Solvents
}

\author{
Sofia Ahmed, Nafeesa Mustaan, Muhammad Ali Sheraz, Syeda Ayesha Ahmed un Nabi, \\ and Iqbal Ahmad
}

Baqai Institute of Pharmaceutical Sciences, Baqai Medical University, 51 Deh Tor, Toll Plaza, Super Highway,

Gadap Road, Karachi 74600, Pakistan

Correspondence should be addressed to Muhammad Ali Sheraz; ali_sheraz80@hotmail.com

Received 26 September 2015; Accepted 17 November 2015

Academic Editor: Giuseppina De Simone

Copyright (C) 2015 Sofia Ahmed et al. This is an open access article distributed under the Creative Commons Attribution License, which permits unrestricted use, distribution, and reproduction in any medium, provided the original work is properly cited.

The present study has been carried out to validate a UV spectrometric method for the assay of tolfenamic acid (TA) in organic solvents. TA is insoluble in water; therefore, a total of thirteen commonly used organic solvents have been selected in which the drug is soluble. Fresh stock solutions of TA in each solvent in a concentration of $1 \times 10^{-4} \mathrm{M}(2.62 \mathrm{mg} \%)$ were prepared for the assay. The method has been validated according to the guideline of International Conference on Harmonization and parameters like linearity, range, accuracy, precision, sensitivity, and robustness have been studied. Although the method was found to be efficient for the determination of TA in all solvents on the basis of statistical data 1-octanol, followed by ethanol and methanol, was found to be comparatively better than the other studied solvents. No change in the stock solution stability of TA has been observed in each solvent for 24 hours stored either at room $\left(25 \pm 1^{\circ} \mathrm{C}\right)$ or at refrigerated temperature $\left(2-8^{\circ} \mathrm{C}\right)$. A shift in the absorption maxima has been observed for TA in various solvents indicating drug-solvent interactions. The studied method is simple, rapid, economical, accurate, and precise for the assay of TA in different organic solvents.

\section{Introduction}

Tolfenamic acid (TA) is a nonsteroidal anti-inflammatory drug (NSAID) that belongs to the family of fenamates and is used in both humans and animals for the management of pain and inflammation [1]. Recently, it has gained tremendous popularity due to its anticancer activity against a variety of cancers [2-7]. TA has also shown potential for use in slowing down the progression of Alzheimer's disease [8-11]. A number of workers have employed various techniques to determine TA in different samples, for example, solutions, milk, serum, blood, and urine [12-22], or to characterize its physicochemical properties [23-28], but still the literature lacks information regarding its analysis in different solvents using a validated method.

TA occurs as a white or slightly yellow crystalline powder and is practically insoluble in water $[29,30]$. The official pharmacopoeial assay method for TA involves direct titration against sodium hydroxide solution [29]. Previously, validated methods for the quantitative analysis of TA, both as a pure compound and in tablet dosage form, have been reported using FTIR and UV spectrometry [31]. Both methods showed good accuracy and precision for the assay of TA with the UV method showing comparatively better results. Both techniques were found to be statistically comparable with the official titrimetric method [31].

The present study has been designed to validate the UV spectrometric assay procedure for the analysis of pure TA in different organic solvents according to the guidelines of International Conference on Harmonization (ICH) [32]. TA is a water insoluble drug and such study would provide useful data which would help in its determination with high accuracy and precision in various pharmaceutical systems incorporating organic solvents.

\section{Materials and Methods}

2.1. Materials. Tolfenamic acid was purchased from SigmaAldrich Company Ltd., Dorset, UK. All the solvents used in 
TABLE 1: List of solvents used for the validation of TA assay in the order of decreasing polarity.

\begin{tabular}{lcccc}
\hline S. number & Name & Purity (\%) & Supplier & Dielectric constant $^{\mathrm{a}}$ \\
\hline$(1)$ & Acetonitrile & $99.9 \%$ & VWR & 36.64 \\
$(2)$ & Methanol & $99.8 \%$ & Merck & 33.00 \\
$(3)$ & Ethanol & $99.8 \%$ & BDH & 25.30 \\
$(4)$ & Acetone & $99.0 \%$ & Merck & 21.01 \\
$(5)$ & 1-Propanol & $99.5 \%$ & Merck & 20.80 \\
$(6)$ & 1-Butanol & $>99.0 \%$ & Merck & 17.84 \\
$(7)$ & 1-Hexanol & $98.0 \%$ & Scharlau & 13.03 \\
$(8)$ & Benzyl alcohol & $>99.0 \%$ & Merck & 11.92 \\
$(9)$ & $1-$ Octanol & $99.5 \%$ & Lab-Scan & 10.30 \\
$(10)$ & Dichloromethane & $99.8 \%$ & Merck & 8.93 \\
$(11)$ & Ethyl acetate & $99.0 \%$ & Merck & 6.08 \\
$(12)$ & Chloroform & $99.5 \%$ & Tedia & 4.81 \\
$(13)$ & Toluene & $99.5 \%$ & & 2.38 \\
\hline
\end{tabular}

${ }^{\mathrm{a}}[33]$.

this study were of analytical grade having the highest degree of purity. The details of the solvents used in this study are reported in Table 1 .

2.2. Thin Layer Chromatography (TLC). TLC was performed to check the purity of TA used in this study according to the method reported in British Pharmacopoeia [29]. The substance $(25 \mathrm{mg}$ ) was dissolved in a mixture of methanol and methylene chloride $(1: 3, \mathrm{v} / \mathrm{v})$ and diluted to $10 \mathrm{~mL}$ with the same mixture and $10 \mu \mathrm{L}$ of the solution was applied to $250 \mu \mathrm{m}$ silica gel $\mathrm{GF}_{254}$ plates. It was developed with the mobile phase up to $2 / 3$ distance of the plate. The plate was dried and viewed under $254 \mathrm{~nm}$ UV lamp (Uvitec, Cambridge, UK).

2.3. Ultraviolet Spectrometry. All absorbance measurements and spectral determinations were carried out on a Shimadzu UV-visible spectrophotometer (model UV-1601) using quartz cell of $10 \mathrm{~mm}$ path length. The cells were employed always in the same orientation using appropriate control solutions in the reference beam. The baseline correction was made by the built-in baseline memory at the initializing period while auto-zero adjustment was made by one-touch operation. The wavelength scale was also calibrated automatically by the instrument. The instrument was calibrated for the absorbance scale according to the method described in British Pharmacopoeia [29], by using $0.057-0.063 \mathrm{~g} / \mathrm{lit}$ of potassium dichromate in $0.005 \mathrm{M}$ sulfuric acid.

The absorbencies of the corresponding series of solutions in each solvent were measured against a reference of the same solvent in the region of 250-400 nm. Quartz cells were closed with a cap to prevent evaporation of the organic solvent during absorbance measurements.

2.4. Preparation of Stock and Test Solutions for Validation Studies. The stock solutions of TA for validation studies were prepared in a concentration of $1.0 \times 10^{-4} \mathrm{M}(2.62 \mathrm{mg} \%)$ in the individual solvent (Table 1 ). The stock solutions were thoroughly stirred each time by the aid of a magnetic stirrer for $30 \mathrm{~min}$. During stirring the solutions were kept in a tightly closed container to avoid evaporation of the organic solvent. The test solutions in each solvent were prepared from the stock by making appropriate dilutions in the concentration range of $1.0-8.0 \times 10^{-5} \mathrm{M}$. The stock solutions and the respective dilutions were found to be completely transparent in appearance. Each time fresh solutions were prepared. The solutions were protected from light and the absorbance was then measured immediately. All experiments were performed in triplicate.

2.5. Validation of the Analytical Method. The UV method for the assay of TA was validated according to the guidelines of ICH [32]. Different parameters of validation for TA were studied which are described as follows.

2.5.1. Linearity and Range. The linearity of the method was determined by preparing calibration curves of absorbance versus the concentration of TA of the test solutions in the concentration range of $1.0-8.0 \times 10^{-5} \mathrm{M}$ for each solvent. The linearity was statistically determined by regression analysis of five concentrations used in triplicate. The linearity range was selected on the basis of absorbance values in the region of around $0.2-0.8$. This range of absorbance is known to provide values with the highest precision [34]. The molar absorptivity and $\mathrm{A}(1 \%, 1 \mathrm{~cm})$ values were also determined from the calibration curve.

2.5.2. Accuracy. The accuracy of the proposed method was determined by adding known concentrations of the drug in the solutions followed by their analysis by the UV spectrometric method. Three different concentrations in triplicate from the studied range were selected and analyzed for the recovery.

2.5.3. Precision. The precision of the developed method was calculated by performing nine determinations at three concentrations covering the specified range. The precision 
was determined by calculating relative standard deviation (\%RSD) of the mean recoveries.

2.5.4. Limit of Detection (LOD) and Limit of Quantitation (LOQ). LOD and LOQ of the developed method were calculated from the standard deviation of the $y$-intercept and slope of the calibration curve using the following formulae:

$$
\begin{aligned}
& \mathrm{LOD}=3.3 \times \frac{\sigma}{S}, \\
& \mathrm{LOQ}=10 \times \frac{\sigma}{S},
\end{aligned}
$$

where $\sigma$ is the standard deviation of the intercept and $S$ is the slope of the calibration curve.

2.5.5. Robustness. The robustness of the method was determined by studying small changes in the assay wavelength $( \pm 2 \mathrm{~nm})$. This parameter was studied thrice in the similar range used for the determination of TA (i.e., $1.0-8.0 \times 10^{-5} \mathrm{M}$ ). The accuracy and precision of the method were determined.

2.5.6. Solution Stability. The stability of stock solutions of TA was studied at room $\left(25 \pm 1^{\circ} \mathrm{C}\right)$ and refrigerated temperature $\left(2-8^{\circ} \mathrm{C}\right)$. The stock solutions of TA were prepared in pure solvents at a concentration of $1 \times 10^{-4} \mathrm{M}(2.62 \mathrm{mg} \%)$. The samples were stored in tightly sealed glass containers protected from light. A $5 \mathrm{~mL}$ aliquot of the sample was taken each time and the absorbencies were measured at 0-, 1-, 2-, 3-, and 24hour time interval.

\section{Results and Discussion}

3.1. Confirmation of Purity of Tolfenamic Acid. In order to study spectrometric characteristics of a compound, it is necessary to confirm the purity of the material to avoid any effect on the position and intensity of the absorption maxima as well as on the validation of the assay method. In the case of TA a thin layer chromatography (TLC) examination was conducted to detect any spots other than that of TA on TLC plates. The TLC test for TA has been carried out according to the method described in British Pharmacopoeia [29]. TA appeared as a single spot confirming the purity of the material.

3.2. Nature of Solvents and Spectral Characteristics of Tolfenamic Acid. The use of solvents in UV-visible spectrometric measurements depends on the nature of the compound to be characterized or analyzed. The solvent must be transparent in the region in which the compound exhibits absorption spectrum. The compound should have enough solubility to obtain a reasonably clear absorption spectrum. It is also important to consider any possible interaction of the solvent with the absorbing molecule to impart a shift in the absorption maxima. It has been reported that polar solvents such as water, alcohols, esters, and ketones (containing lone pair of electrons) tend to obscure vibrational spectra. The nonpolar solvents such as cyclohexane, chloroform, and benzene give spectra somewhat similar to that of a gas (better band resolution) [35]. The maximum absorption wavelength of the absorption band depends on the degree of solutesolvent interaction and the nature of solvent [36-39]. The solvent dependent spectral shifts arise from either nonspecific (dielectric enrichment) or specific (e.g., hydrogen bonding) solute-solvent interactions. Considering the interactions between the solute and solvent molecule and the intensity of these interactions, a change in the absorption spectrum of the molecule (e.g., $\lambda_{\max }$ and $\epsilon_{\max }$ ) can be expected. Such a change has been described as solvatochromism [40]. The organic solvents have a different polar character as indicated by the dielectric constant of the medium. It has been observed that an electronic transition of a compound may lead to a modification of the charge distribution by the solvent used. This would result in some change in the position and intensity of the absorption maxima depending on the nature of the solvent. The extent of solute-solvent interaction would give an indication of the type of electronic transition undergone by the molecule [41].

The lower wavelength limit of common solvents in the $\mathrm{UV}$ and visible spectra strongly depends on the purity of the solvent (Table 1). For example, ethanol and the hydrocarbon solvents are frequently contaminated with benzene which absorbs below $280 \mathrm{~nm}$ [35]. Therefore, the highest/spectroscopic grade solvents should always be used for the measurement of the absorption spectra of organic compounds; otherwise the true spectral characteristics of a compound may not be obtained due to the presence of interfering impurities.

The spectral characteristics of TA including the value of absorption maxima, respective molar absorptivities $(\epsilon)$, and specific absorbance $[A(1 \%, 1 \mathrm{~cm})]$ in various organic solvents are reported in Table 2. A consideration of the values of absorption maxima of TA in various organic solvents shows that their $\lambda_{1 \max }$ range from 286 to $294 \mathrm{~nm}$ and $\lambda_{2 \max }$ from 332 to $354 \mathrm{~nm}$ (Figure 1, Table 2) with regression values $\left(R^{2}\right)$ of $0.99905-0.99988$ showing very small scatter of the points around the calibration curves (Table 3 ).

Similarly, a variation in the values of $\epsilon_{\max }$ in these solvents is also observed (Table 2). This is probably due to the degree of interaction between the solute and the solvent to cause a shift in the absorption maxima with accompanying change in the intensity of absorption as indicated by the values of $\epsilon_{\max }$. The high values of $\epsilon_{\max }$ indicate $\pi-\pi^{*}$ electronic transition in the molecule. The values of $\epsilon_{\lambda_{1}}$ range from 7930 to $10960 \mathrm{M}^{-1} \mathrm{~cm}^{-1}$ and those of $\epsilon_{\lambda_{2}}$ from 5310 to $8967 \mathrm{M}^{-1} \mathrm{~cm}^{-1}$.

3.3. Validation of the Assay Method. The UV spectrometric assay of TA in various solvents has been validated according to the guidelines of $\mathrm{ICH}$ [32], including the following parameters.

3.3.1. Linearity. Linearity determines the ability of the method to obtain the results that are directly proportional to the concentration of the analyte within a given range by plotting a calibration curve. TA is 2-[(3-chloro-2methylphenyl)amino]benzoic acid and gives two peaks in 
TABLE 2: Absorption maxima and molar absorptivities of TA in organic solvents.

\begin{tabular}{|c|c|c|c|c|c|c|}
\hline \multirow{2}{*}{ Solvent } & \multicolumn{2}{|c|}{ Absorption maxima (nm) } & \multicolumn{2}{|c|}{ Molar absorptivity $\left(\mathrm{M}^{-1} \mathrm{~cm}^{-1}\right)$} & \multicolumn{2}{|c|}{$A(1 \%, 1 \mathrm{~cm})$} \\
\hline & $\lambda_{1 \max }$ & $\lambda_{2 \max }$ & $\epsilon \lambda_{1 \max }$ & $\epsilon \lambda_{2 \max }$ & $\lambda_{1 \text { max }}$ & $\lambda_{2 \max }$ \\
\hline Acetonitrile & 286 & 343 & 9083 & 6960 & 352 & 266 \\
\hline Methanol & 289 & 335 & 10371 & 6328 & 431 & 242 \\
\hline Ethanol & 289 & 338 & 10100 & 6030 & 390 & 230 \\
\hline Acetone & - & 347 & - & 8781 & 336 & 336 \\
\hline 1-Propanol & 288 & 343 & 10849 & 7512 & 438 & 287 \\
\hline 1-Butanol & 294 & 332 & 10029 & 5310 & 384 & 203 \\
\hline 1-Hexanol & 289 & 344 & 7926 & 5380 & 300 & 205 \\
\hline Benzyl alcohol & 289 & 352 & 9386 & 7711 & 359 & 295 \\
\hline 1-Octanol & 290 & 343 & 9118 & 5884 & 348 & 225 \\
\hline Dichloromethane & 287 & 350 & 10956 & 8967 & 416 & 343 \\
\hline Ethyl acetate & 287 & 343 & 8995 & 6593 & 353 & 252 \\
\hline Chloroform & 288 & 351 & 8929 & 4620 & 338 & 176 \\
\hline Toluene & 288 & 354 & 8539 & 7141 & 326 & 273 \\
\hline
\end{tabular}

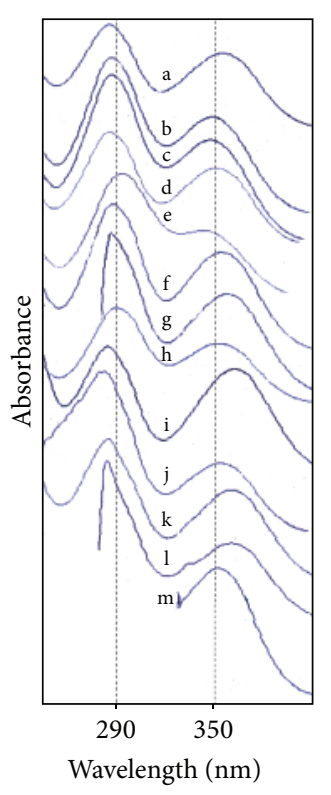

FIGURE 1: Variations in the absorption maxima of TA in organic solvents. (a) Acetonitrile, (b) methanol, (c) ethanol, (d) 1-propanol, (e) 1-butanol, (f) 1-hexanol, (g) benzyl alcohol, (h) 1-octanol, (i) dichloromethane, $(\mathrm{j})$ ethyl acetate, $(\mathrm{k})$ chloroform, (l) toluene, and (m) acetone.

the region of $280-360 \mathrm{~nm}$ (Figure 1). The short wavelength peak in the region below $300 \mathrm{~nm}$ is more prominent with a greater intensity than the one present above $300 \mathrm{~nm}$. Therefore, calibration curves of TA in each solvent have been prepared with respect to the short wavelength peak in the majority of solvents (Table 2). On the contrary, in the solvent that showed some interference or has a cutoff point near or above the prominent peak of TA such as acetone $(330 \mathrm{~nm})$, benzyl alcohol $(282 \mathrm{~nm})$, and toluene $(286 \mathrm{~nm})$, it has been assayed and validated with respect to the long wavelength peak (Figure 1). Although the calibration curves in benzyl alcohol and toluene have been prepared with respect to the

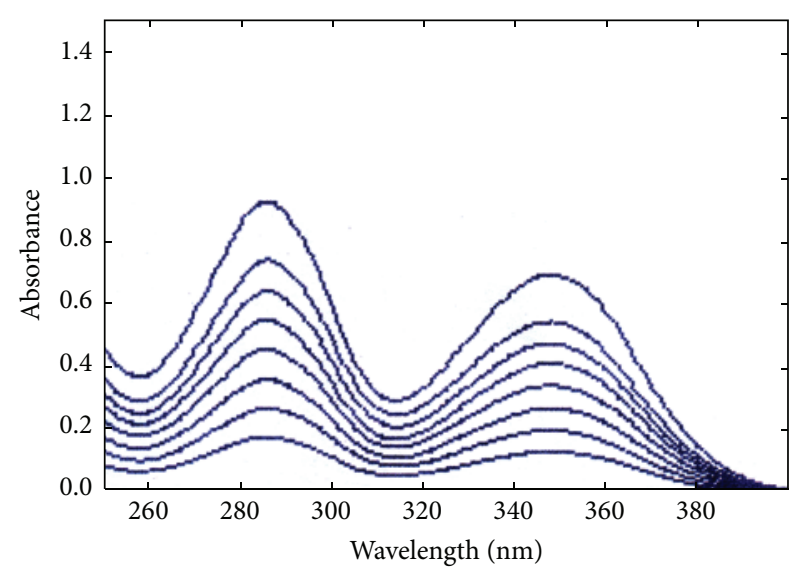

FIGURE 2: Overlay spectra of TA in acetonitrile.

short wavelength peak due to their interfering cutoff points they have further been validated for TA assay using the long wavelength peak. A linear relationship has been found for TA in each solvent and the statistical data are reported in Table 3. The intercept values are significantly close to zero in each case thus confirming the peak purity of TA. The overlay spectra of TA in acetonitrile are shown in Figure 2.

3.3.2. Range. It is defined as the interval between the upper and lower concentrations of the analyte that have been demonstrated to be determined with acceptable precision, accuracy, and linearity. The absorbance values in the range of 0.2-0.8 are known to offer the highest precision [34]. Therefore, similar pattern has also been followed in this study in determining the range of TA in each solvent. The ranges for the assay of TA in each solvent are reported in Table 3 which corresponds well to the points in calibration curves.

3.3.3. Accuracy. The accuracy of an analytical method is defined as the degree to which the determined value of 


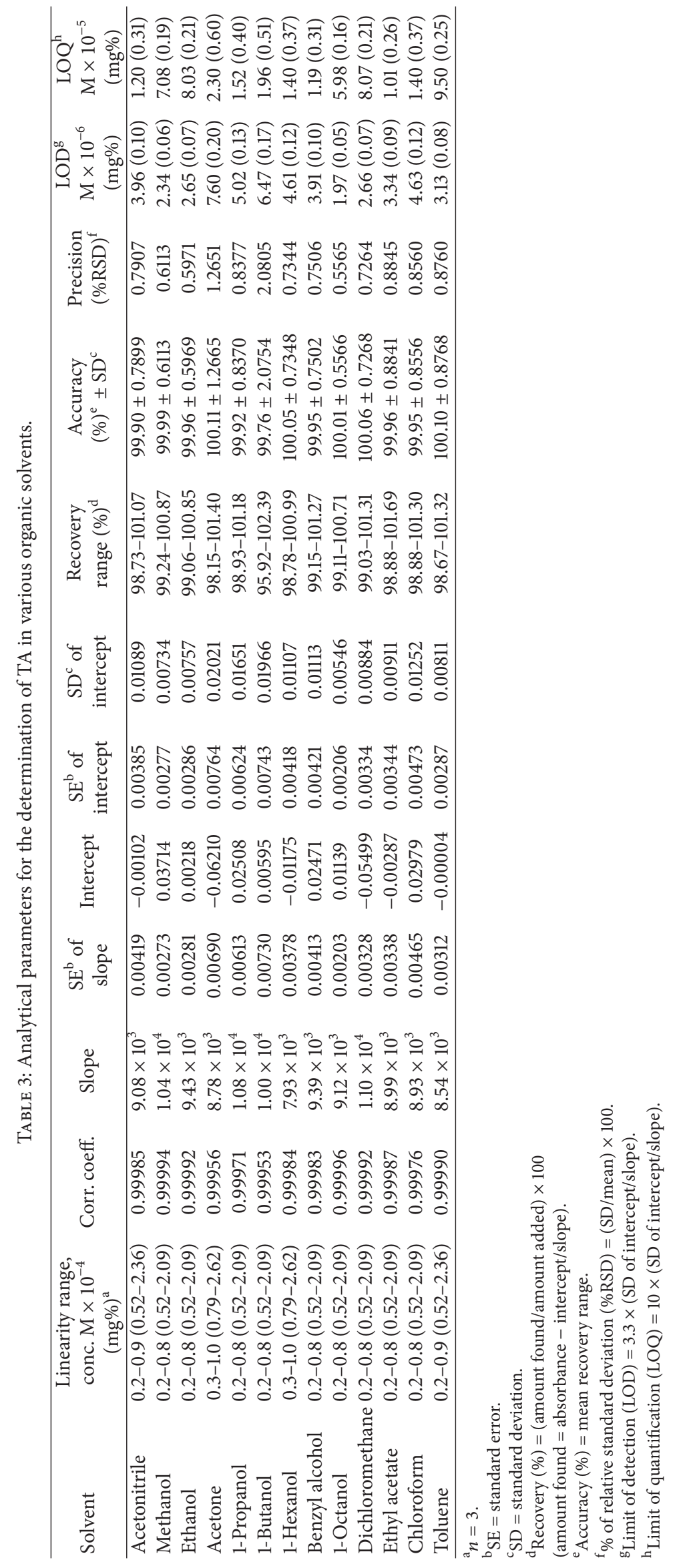


an analyte in a sample corresponds to the true value. The results for the percent recovery of TA in different organic solvents are reported in Table 3. Although the results show good accuracy for TA in each solvent comparatively the mean recovery in 1-octanol followed by ethanol and methanol is better than that of the others due to minimum standard deviations. The standard deviations are small in all cases indicating that the method can be used with high accuracy for the determination of TA in the studied organic solvents.

3.3.4. Precision. Precision of an analytical method is the closeness of agreement between a series of measurements obtained from multiple samples of the studied drug under prescribed conditions. The results for the precision of the method for the assay of TA in various solvents are reported in Table 3. These indicate that the \%RD in the majority of cases is less than $2 \%$ and is minimum in the case of 1-octanol with nearly the same values in ethanol and methanol. Thus the studied method is highly reliable for the assay of TA in different solvents.

3.3.5. LOD. It is the lowest concentration of an analyte in a sample that can be detected but not necessarily quantified. It is considered as limit test that indicates that the analyte is above or below a certain value which is usually expressed as percentage of the analyte in the sample. The LOD of TA in each solvent is reported in Table 3. The minimum detection limit of $1.97 \times 10^{-6} \mathrm{M}(0.05 \mathrm{mg} \%)$ has been found in 1-octanol while the highest of $6.47 \times 10^{-6} \mathrm{M}(0.17 \mathrm{mg} \%)$ has been found in 1-butanol. This indicates that the UV spectrometric technique is highly sensitive for the detection of TA in various organic solvents.

3.3.6. LOQ. The LOQ determines the lowest concentration of an analyte in a sample that can be quantified with acceptable precision and accuracy under the documented operational conditions of the drug being assayed. The minimum quantification limit of $5.98 \times 10^{-6} \mathrm{M}(0.16 \mathrm{mg} \%)$ has been found in 1-octanol while the highest of $1.96 \times 10^{-5} \mathrm{M}(0.51 \mathrm{mg} \%)$ has been found in 1-butanol. The values of LOQ of TA in each solvent are reported in Table 3. All solvents have been found to correspond well with the quantification of TA by UV spectrometric technique indicating that the method is accurate and precise for its assay.

3.3.7. Robustness. The robustness of an analytical method is a measure of its capacity to obtain acceptable results when perturbed by small but deliberate variations. It is basically an indicator of method suitability and reliability during normal use. Absorbance of a solution is dependent upon wavelength, solvent, $\mathrm{pH}$, and temperature. Therefore, these parameters should remain constant throughout the course of the analysis; otherwise significant errors may arise in the quantitative analysis of the samples [34]. In the present study, the reliability of the method has been tested by determining the absorption maxima in each solvent and by changing the assay wavelengths at room temperature $\left(25 \pm 1^{\circ} \mathrm{C}\right)$. The results showed that small changes in the wavelength of absorption
TABLE 4: Robustness of the proposed method in different organic solvents.

\begin{tabular}{|c|c|c|c|}
\hline Solvents & $\begin{array}{c}\text { Wavelength } \\
\left(\lambda_{\max } \pm 2 \mathrm{~nm}\right)^{\mathrm{a}}\end{array}$ & Accuracy $(\%) \pm S D$ & $\begin{array}{c}\text { Precision } \\
(\% \mathrm{RSD})\end{array}$ \\
\hline \multirow{2}{*}{ Acetonitrile } & 284 & $100.02 \pm 0.4554$ & 0.4553 \\
\hline & 288 & $100.03 \pm 0.5216$ & 0.5215 \\
\hline \multirow{2}{*}{ Methanol } & 288 & $99.91 \pm 0.7512$ & 0.7519 \\
\hline & 292 & $99.88 \pm 1.0125$ & 1.0137 \\
\hline \multirow{2}{*}{ Ethanol } & 288 & $99.93 \pm 0.7414$ & 0.7420 \\
\hline & 292 & $99.87 \pm 1.2148$ & 1.2164 \\
\hline \multirow{2}{*}{ Acetone } & 345 & $100.29 \pm 2.8852$ & 2.8769 \\
\hline & 349 & $100.33 \pm 3.3030$ & 3.2920 \\
\hline \multirow{2}{*}{ 1-Propanol } & 286 & $99.90 \pm 0.9924$ & 0.9934 \\
\hline & 290 & $99.69 \pm 2.4774$ & 2.4851 \\
\hline \multirow{2}{*}{ 1-Butanol } & 292 & $99.73 \pm 2.1447$ & 2.1506 \\
\hline & 296 & $99.99 \pm 1.4541$ & 1.4543 \\
\hline \multirow{2}{*}{ 1-Hexanol } & 287 & $100.06 \pm 0.9026$ & 0.9021 \\
\hline & 291 & $100.05 \pm 0.8686$ & 0.8681 \\
\hline \multirow{4}{*}{ Benzyl alcohol } & 287 & $99.90 \pm 1.1057$ & 1.1068 \\
\hline & 291 & $99.94 \pm 0.7845$ & 0.7850 \\
\hline & 350 & $100.14 \pm 1.4184$ & 1.4165 \\
\hline & 354 & $100.14 \pm 1.4571$ & 1.4550 \\
\hline \multirow{2}{*}{ 1-Octanol } & 288 & $99.91 \pm 0.7796$ & 0.7803 \\
\hline & 292 & $99.89 \pm 0.9320$ & 0.9330 \\
\hline \multirow{2}{*}{ Dichloromethane } & 285 & $100.16 \pm 1.3225$ & 1.3203 \\
\hline & 289 & $100.18 \pm 1.4535$ & 1.4508 \\
\hline \multirow{2}{*}{ Ethyl acetate } & 285 & $99.82 \pm 1.8881$ & 1.8914 \\
\hline & 289 & $99.84 \pm 1.7719$ & 1.7748 \\
\hline \multirow{2}{*}{ Chloroform } & 286 & $99.66 \pm 3.1248$ & 3.1353 \\
\hline & 290 & $99.67 \pm 3.1182$ & 3.1285 \\
\hline \multirow{4}{*}{ Toluene } & 286 & $99.81 \pm 1.3132$ & 1.3157 \\
\hline & 290 & $100.10 \pm 0.8523$ & 0.8514 \\
\hline & 352 & $100.04 \pm 0.5126$ & 0.5124 \\
\hline & 356 & $100.04 \pm 0.5611$ & 0.5608 \\
\hline
\end{tabular}

${ }^{\mathrm{a}} \lambda_{\max }$ for each solvent are reported in Table 2.

maxima do not affect the accuracy and precision of the assay of TA (Table 4). This indicates that the method is robust under the studied conditions in the majority of the solvents. The highest robustness has been found in acetonitrile whereas the lowest has been found in chloroform followed by acetone (Table 4).

3.3.8. Solution Stability. The solution stability is a measure of the extent to which the studied drug is stable in a solvent being used for the assay over a particular period of time under specified conditions. It is an essential requirement that the analyte should not undergo any chemical change and should remain stable in the particular solvent [34].

The study of TA was carried out at room temperature $(25 \pm$ $1^{\circ} \mathrm{C}$ ) and refrigerated temperature $\left(2-8^{\circ} \mathrm{C}\right)$. The consistency in absorbance indicated the stability of TA solutions. In all solvents no significant change has been observed in the absorbance of TA after 24 hours of storage either at room temperature or in a refrigerator. However, in spite of the stability of TA in the organic solvents for at least 24 hours, fresh solutions were used for the validation study. 


\section{Conclusion}

The present study has employed thirteen commonly used solvents for the validation of a UV spectrometric method for the determination of TA. The results indicated that the method is accurate, precise, robust, economical, and rapid for the assay of TA with a stock solution stability of 24 hours in each solvent. TA exhibits two peaks in the UV region of $280-360 \mathrm{~nm}$. The major short wavelength peak is in the region of $285-295 \mathrm{~nm}$ that showed good results for the assay of TA. Those solvents that have a cutoff point in this region or interfere with the major peak can also be used for the determination of TA with respect to the minor long wavelength peak in the region of 335-355 nm.

The results of this study highlight the effect of different solvents on the spectral characteristics of organic molecules of pharmaceutical importance. Some shifts in the absorption maxima of TA have been noted probably due to drugsolvent interaction while absorptivity constants of TA in each solvent have also been determined. These shifts can affect the wavelengths used for the assay of a compound and, therefore, it is necessary to use a particular solvent for assay purpose. It is also necessary to confirm the purity of the solvent used for assay and its interference in the spectral region of the compound to be studied. A detailed investigation of the effect of solvent parameters on the spectral characteristics of a compound is required to develop an understanding of the changes observed. Such study would help the pharmaceutical formulators and analysts to determine TA in pharmaceutical systems incorporating organic solvents.

\section{Conflict of Interests}

There is no conflict of interests regarding the publication of this paper.

\section{References}

[1] S. C. Sweetman, Martindale: The Complete Drug Reference, Pharmaceutical Press, London, UK, 36th edition, 2009.

[2] J. Colon, M. R. Basha, R. Madero-Visbal et al., "Tolfenamic acid decreases c-Met expression through Sp proteins degradation and inhibits lung cancer cells growth and tumor formation in orthotopic mice," Investigational New Drugs, vol. 29, no. 1, pp. 41-51, 2011.

[3] D. Eslin, U. T. Sankpal, C. Lee et al., "Tolfenamic acid inhibits neuroblastoma cell proliferation and induces apoptosis: a novel therapeutic agent for neuroblastoma," Molecular Carcinogenesis, vol. 52, no. 5, pp. 377-386, 2013.

[4] J.-H. Kim, J.-Y. Jung, J.-H. Shim et al., "Apoptotic effect of tolfenamic acid in KB human oral cancer cells: possible involvement of the p38 MAPK pathway," Journal of Clinical Biochemistry and Nutrition, vol. 47, no. 1, pp. 74-80, 2010.

[5] X. Liu, M. Abdelrahim, A. Abudayyeh, P. Lei, and S. Safe, "The nonsteroidal anti-inflammatory drug tolfenamic acid inhibits BT474 and SKBR3 breast cancer cell and tumor growth by repressing erbB2 expression," Molecular Cancer Therapeutics, vol. 8, no. 5, pp. 1207-1217, 2009.

[6] S. U. Kang, Y. S. Shin, H. S. Hwang, S. J. Baek, S.-H. Lee, and C.-H. Kim, "Tolfenamic acid induces apoptosis and growth inhibition in head and neck cancer: involvement of NAG-1 expression," PLoS ONE, vol. 7, no. 4, Article ID e34988, 2012.

[7] J.-H. Shim, J.-A. Shin, J.-Y. Jung et al., "Chemopreventive effect of tolfenamic acid on KB human cervical cancer cells and tumor xenograft by downregulating specificity protein 1," European Journal of Cancer Prevention, vol. 20, no. 2, pp. 102-111, 2011.

[8] L. I. Adwan, R. Basha, M. Abdelrahim, G. M. Subaiea, and N. H. Zawia, "Tolfenamic acid interrupts the de novo synthesis of the $\beta$-amyloid precursor protein and lowers amyloid beta via a transcriptional pathway," Current Alzheimer Research, vol. 8, no. 4, pp. 385-392, 2011.

[9] L. Adwan, G. M. Subaiea, and N. H. Zawia, "Tolfenamic acid downregulates BACE1 and protects against lead-induced upregulation of Alzheimer's disease related biomarkers," Neuropharmacology, vol. 79, pp. 596-602, 2014.

[10] G. M. Subaiea, B. H. Alansi, D. A. Serra, M. Alwan, and N. H. Zawia, "The ability of tolfenamic acid to penetrate the brain: a model for testing the brain disposition of candidate Alzheimer's drugs using multiple platforms," Current Alzheimer Research, vol. 8, no. 8, pp. 860-867, 2011.

[11] G. M. Subaiea, A. H. Ahmed, L. I. Adwan, and N. H. Zawia, "Reduction of amyloid- $\beta$ deposition and attenuation of memory deficits by tolfenamic acid," Journal of Alzheimer's Disease, vol. 43, no. 2, pp. 425-433, 2015.

[12] N. S. Abdelwahab, N. W. Ali, M. M. Zaki, and M. Abdelkawy, "Validated chromatographic methods for simultaneous determination of tolfenamic acid and its major impurities," Journal of Chromatographic Science, vol. 53, no. 4, pp. 484-491, 2015.

[13] E. Dubreil-Chéneau, Y. Pirotais, M. Bessiral, B. Roudaut, and E. Verdon, "Development and validation of a confirmatory method for the determination of 12 non steroidal antiinflammatory drugs in milk using liquid chromatographytandem mass spectrometry," Journal of Chromatography A, vol. 1218, no. 37, pp. 6292-6301, 2011.

[14] P. Gallo, S. Fabbrocino, F. Vinci et al., "Multi-residue determination of non-steroidal anti-inflammatory drug residues in animal serum and plasma by HPLC and photo-diode array detection," Journal of Chromatographic Science, vol. 44, no. 10, pp. 585-590, 2006.

[15] P. Gallo, S. Fabbrocino, G. Dowling et al., "Confirmatory analysis of non-steroidal anti-inflammatory drugs in bovine milk by high-performance liquid chromatography with fluorescence detection," Journal of Chromatography A, vol. 1217, no. 17, pp. 2832-2839, 2010.

[16] P. C. Ioannou, N. V. Rusakova, D. A. Andrikopoulou, K. M. Glynou, and G. M. Tzompanaki, "Spectrofluorimetric determination of anthranilic acid derivatives based on terbium sensitized fluorescence," Analyst, vol. 123, no. 12, pp. 2839-2843, 1998.

[17] Y. P. Kang, J. Yu, Y. Huh et al., "Development of high performance liquid chromatography-ultraviolet detection method for screening mebendazole, clorsulon, diaveridine, and tolfenamic acid in animal-based food samples," Drug Testing and Analysis, vol. 6, no. 3, pp. 246-256, 2014.

[18] N. Karu, J. P. Hutchinson, G. W. Dicinoski et al., "Determination of pharmaceutically related compounds by suppressed ion chromatography. IV. Interfacing ion chromatography with universal detectors," Journal of Chromatography A, vol. 1253, pp. 44-51, 2012. 
[19] C. I. Kosma, D. A. Lambropoulou, and T. A. Albanis, "Investigation of PPCPs in wastewater treatment plants in Greece: occurrence, removal and environmental risk assessment," The Science of the Total Environment, vol. 466-467, pp. 421-438, 2014.

[20] A. Mattei and T. Li, "Polymorph formation and nucleation mechanism of tolfenamic acid in solution: an investigation of pre-nucleation solute association," Pharmaceutical Research, vol. 29, no. 2, pp. 460-470, 2012.

[21] M. M. Parrilla Vázquez, P. Parrilla Vázquez, M. Martínez Galera, M. D. Gil García, and A. Uclés, "Ultrasound-assisted ionic liquid dispersive liquid-liquid microextraction coupled with liquid chromatography-quadrupole-linear ion trap-mass spectrometry for simultaneous analysis of pharmaceuticals in wastewaters," Journal of Chromatography A, vol. 1291, pp. 19-26, 2013.

[22] J. S. Ra, S.-Y. Oh, B. C. Lee, and S. D. Kim, "The effect of suspended particles coated by humic acid on the toxicity of pharmaceuticals, estrogens, and phenolic compounds," Environment International, vol. 34, no. 2, pp. 184-192, 2008.

[23] S. Ahmed, M. A. Sheraz, C. Yorucu, and I. U. Rehman, "Quantitative determination of tolfenamic acid and its pharmaceutical formulation using FTIR and UV spectrometry," Central European Journal of Chemistry, vol. 11, no. 9, pp. 1533-1541, 2013.

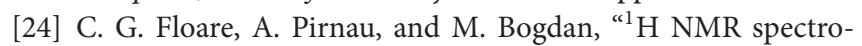
scopic characterization of inclusion complexes of tolfenamic and flufenamic acids with $\beta$-cyclodextrin," Journal of Molecular Structure, vol. 1044, pp. 72-78, 2013.

[25] H. Istanbullu, S. Ahmed, M. A. Sheraz, and I. U. Rehman, "Development and characterization of novel polyurethane films impregnated with tolfenamic acid for therapeutic applications," BioMed Research International, vol. 2013, Article ID 178973, 8 pages, 2013.

[26] S. Jabeen, T. J. Dines, S. A. Leharne, and B. Z. Chowdhry, "Raman and IR spectroscopic studies of fenamates-conformational differences in polymorphs of flufenamic acid, mefenamic acid and tolfenamic acid," Spectrochimica Acta-Part A: Molecular and Biomolecular Spectroscopy, vol. 96, pp. 972-985, 2012.

[27] M. A. Sheraz, S. Ahmed, and I. U. Rehman, "Effect of pH, polymer concentration and molecular weight on the physical state properties of tolfenamic acid," Pharmaceutical Development and Technology, vol. 20, no. 3, pp. 352-360, 2015.

[28] P. Thybo, J. Kristensen, and L. Hovgaard, "Characterization and physical stability of tolfenamic acid-PVP K30 solid dispersions," Pharmaceutical Development and Technology, vol. 12, no. 1, pp. 43-53, 2007.

[29] British Pharmacopoeia, Monograph on Tolfenamic Acid, The Stationary Office, British Pharmacopoeia Commission Office, London, UK, 2013.

[30] A. C. Moffat, M. D. Osselton, and B. Widdop, Clarke's Analysis of Drugs and Poisons, Pharmaceutical Press, London, UK, 4th edition, 2011.

[31] S. Ahmed, M. A. Sheraz, and I. U. Rehman, "Studies on tolfenamic acid-chitosan intermolecular interactions: effect of $\mathrm{pH}$, polymer concentration and molecular weight," AAPS PharmSciTech, vol. 14, no. 2, pp. 870-879, 2013.

[32] ICH, "ICH harmonised tripartite guideline: validation of analytical procedures: text and methodology Q2(R1)," in Proceedings of the International Conference on Harmonization of Technical Requirements for Registration of Pharmaceuticals for Human Use, Geneva, Switzerland, 2005.

[33] D. R. Lide, CRC Handbook of Chemistry and Physics, Taylor \& Francis, Boca Raton, Fla, USA, 87th edition, 2007.
[34] S. Hansen, S. Pedersen-Bjergaard, and K. Rasmussen, Introduction to Pharmaceutical Chemical Analysis, John Wiley \& Sons, Chichester, UK, 2012.

[35] D. A. Skoog, D. M. West, F. J. Holler, and S. R. Crouch, Fundamentals of Analytical Chemistry, Cengage Learning, Brooks/Cole, Belmont, Calif, USA, 2014.

[36] S. E. DeBolt and P. A. Kollman, "A theoretical examination of solvatochromism and solute-solvent structuring in simple alkyl carbonyl compounds. Simulations using statistical mechanical free energy perturbation methods," Journal of the American Chemical Society, vol. 112, no. 21, pp. 7515-7524, 1990.

[37] J. E. Dubois, E. Goetz, and A. Bienvenüe, "Influence des solvants sur la transition $n \rightarrow \pi^{*}$ des cétones saturées," Spectrochimica Acta, vol. 20, no. 12, pp. 1815-1828, 1964.

[38] T. Fox and N. Rosch, "The calculation of solvatochromic shifts: the $\mathrm{n}-\pi^{*}$ transition of acetone," Chemical Physics Letters, vol. 191, no. 1-2, pp. 33-37, 1992.

[39] C. Reichardt, Solvents and Solvent Effects in Organic Chemistry, Wiley-VCH, Weinheim, Germany, 2003.

[40] W.-G. Han, T. Liu, F. Himo et al., "A theoretical study of the UV/visible absorption and emission solvatochromic properties of solvent-sensitive dyes," ChemPhysChem, vol. 4, no. 10, pp. 1084-1094, 2003.

[41] F. Rouessac and A. Rouessac, Chemical Analysis, Modern Instrumentation Methods and Techniques, John Wiley \& Sons, Chichester, UK, 2007. 

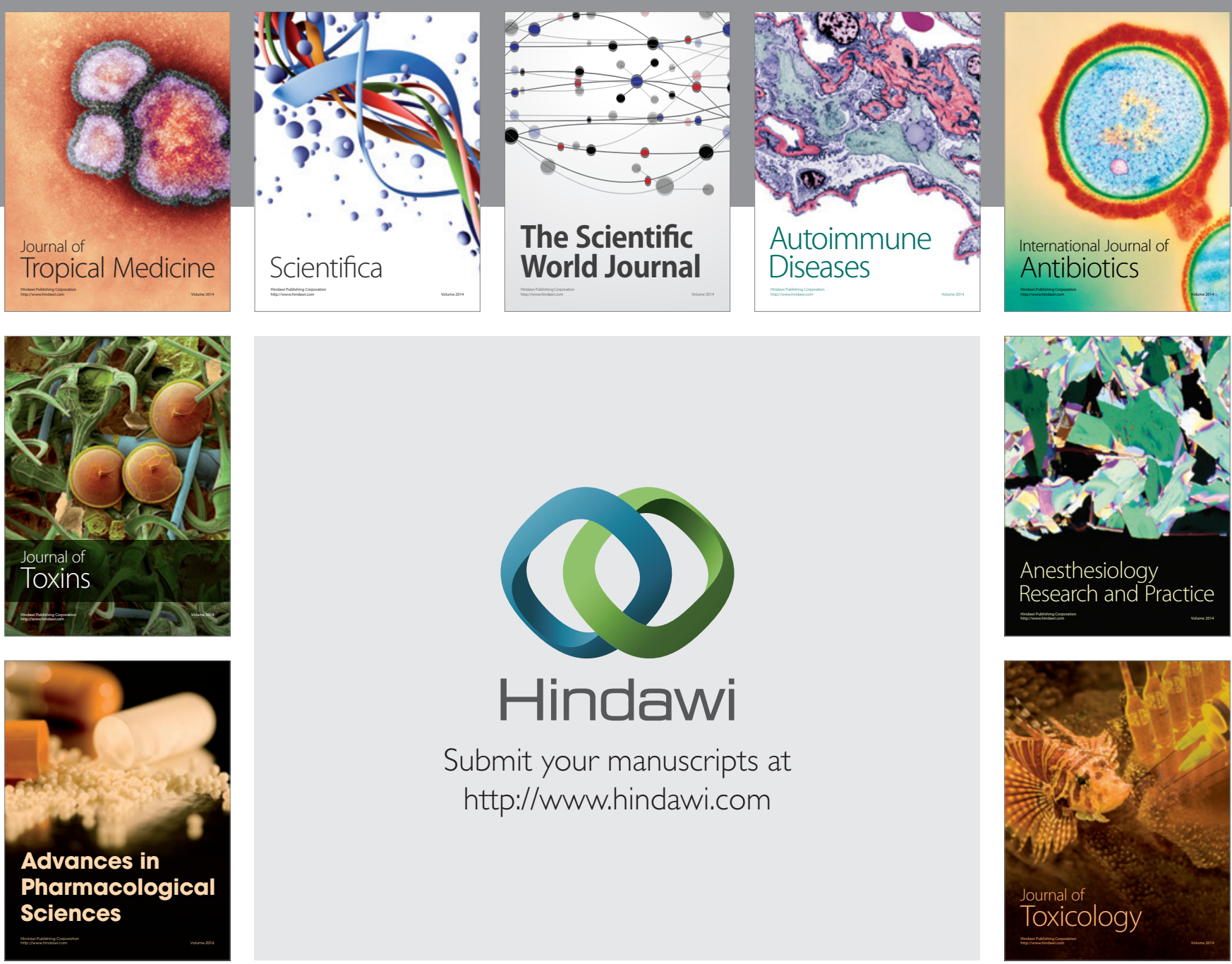

\section{Hindawi}

Submit your manuscripts at

http://www.hindawi.com
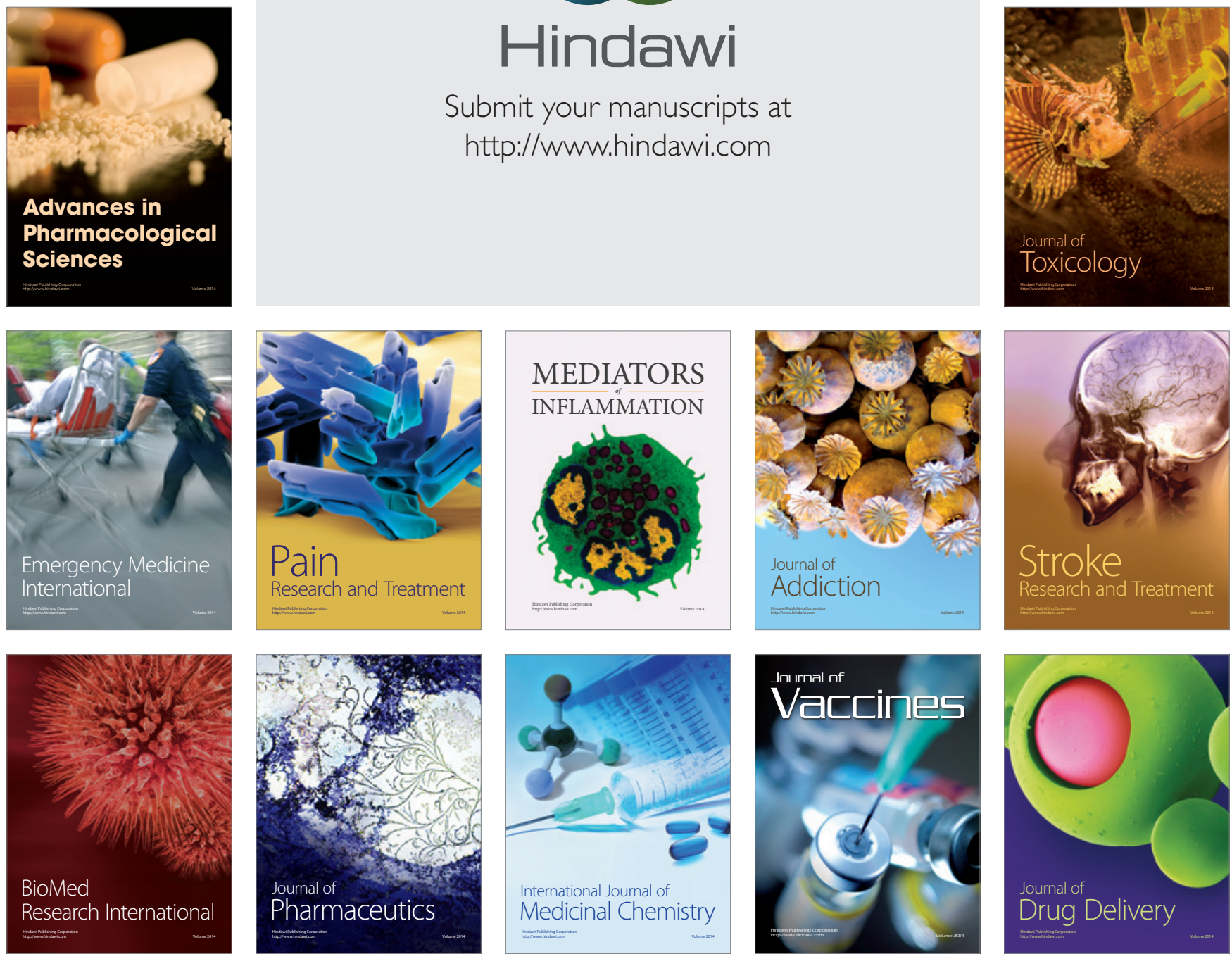